\title{
In Vitro Anti-Inflammatory and Wound-Healing Potential of a Phyllostachys edulis Leaf Extract - Identification of Isoorientin as an Active Compound
}

Authors

Affiliations
Jonas Wedler ${ }^{1}$, Tony Daubitz ${ }^{1}$, Götz Schlotterbeck ${ }^{2}$, Veronika Butterweck ${ }^{1}$

${ }^{1}$ Institute for Pharma Technology, School of Life Sciences, University of Applied Sciences Northwestern Switzerland, Muttenz, Switzerland

${ }^{2}$ Institute for Chemistry and Bioanalytics, School of Life Sciences, University of Applied Sciences Northwestern Switzerland, Muttenz, Switzerland

\author{
Key words \\ - Phyllostachys edulis \\ - Poaceae \\ - bamboo \\ wound healing \\ - anti-inflammatory \\ - time-lapse microscopy
}

$\begin{array}{ll}\text { received } & \text { July } 15,2014 \\ \text { revised } & \text { Sept. 18, } 2014 \\ \text { accepted } & \text { Sept. 22, } 2014\end{array}$

\section{Bibliography}

Dol http://dx.doi.org/ 10.1055/s-0034-1383195 Published online October 15, 2014

Planta Med 2014; 80: 1678-1684 (c) Georg Thieme Verlag KG Stuttgart · New York . ISSN 0032-0943

\section{Correspondence}

Prof. Dr. Veronika Butterweck

Institute for Pharma Technology School of Life Sciences

University of Applied Sciences

Northwestern Switzerland

Gründenstraße 40

4132 Muttenz

Switzerland

Phone: + 41614674689

Fax: +41614674701

veronika.butterweck@fhnw.ch

\section{Abstract \\ $\nabla$}

Extracts prepared from the leaves of Phyllostachys edulis (bamboo) have received attention in pharmacological research due to their potent antitumor, anti-inflammatory, antimicrobial, and antiulcerogenic activities. In this study, anti-inflammatory effects of a bamboo leaf extract on tumor necrosis factor alpha-induced overproduction of interleukin 8, vascular endothelial growth factor, and interleukin 6 in immortalized human keratinocytes were investigated for the first time. In addition, wound-healing effects were evaluated in 3T3-swiss albino mouse fibroblasts. Bamboo leaf extract and isoorientin inhibited the tumor necrosis factor alpha-induced release of interleukin 8 and vascular endothelial growth factor. Furthermore, isoorientin dose-dependently reduced levels of interleukin 6 in tumor necrosis factor alpha$\alpha$-treated immortalized human keratinocytes cells. Wound healing was evaluated using a mod-

\section{Introduction}

$\nabla$

Wounds are defined as physical injuries that result in an opening or break of the skin that causes a disturbance in the normal skin anatomy and function [1]. Wound healing can be grouped roughly into three different phases: the initial inflammation is followed by the granulation phase connected to reepithelialization and, in the end, the long-term process of remodeling [2]. The inflammations' onset happens immediately after injury. It is highly regulated and depends upon proinflammatory mechanisms, which are gradually counteracted by various anti-inflammatory pathways mediated by factors like interleukin 10 (IL-10), hormones, and neurotransmitters [2]. If the anti-inflammatory response prevails, the process turns into the next stage of granulation, and fibroblasts and keratinocytes migrate into the ification of the classical scratch assay. For evaluation of the wound gap, a new computerized method based on time-lapse microscopy was developed. It was shown that bamboo leaf extract $(10 \mu \mathrm{g} / \mathrm{mL})$ improved wound closure by $28 \%$ $(12 \mathrm{~h})$ and $54 \%(24 \mathrm{~h})$, respectively. In concentrations of $50 \mu \mathrm{g} / \mathrm{mL}$ and above, bamboo leaf extract inhibited cell migration without affecting cell viability. Isoorientin $(10 \mu \mathrm{M})$ improved wound closure by $29 \%$ ( $12 \mathrm{~h}$ ) and 56\% (24 h), respectively. Comparable to bamboo leaf extract, higher concentrations of isoorientin prevented cell migration. It is suggested that bamboo leaf extract as well as isoorientin have a dual activity - in higher doses, they show anti-inflammatory effects, and in lower concentrations, they exert anti-angiogenic activities.

Supporting information available online at http://www.thieme-connect.de/products

wound. Angiogenesis mediates capillaries to replace the fibrin matrix with granulation tissue, which depicts a substrate for keratinocyte migration at later stages. Maturation of the keratinocytes leads to a restoration of the epithelium's barrier function [3]. Contraction of the wound is done by fibroblasts located at the wound's edge that differentiate into myofibroblasts producing extracellular matrix (ECM) [3]. The final stage is specified by the remodeling of the tissue's architecture [3].

In terms of wound healing, interleukin 6 (IL-6), interleukin 8 (IL-8), and vascular endothelial growth factor (VEGF) are key players in these processes. IL-6 has both pro- and anti-inflammatory properties. Tumor necrosis factor alpha- $\alpha$ (TNF$\alpha$ ) depicts a physiologic stimulus to IL-6 [4]. As a member of the chemokine family, IL- 8 possesses chemotactic properties attracting neutrophils. 


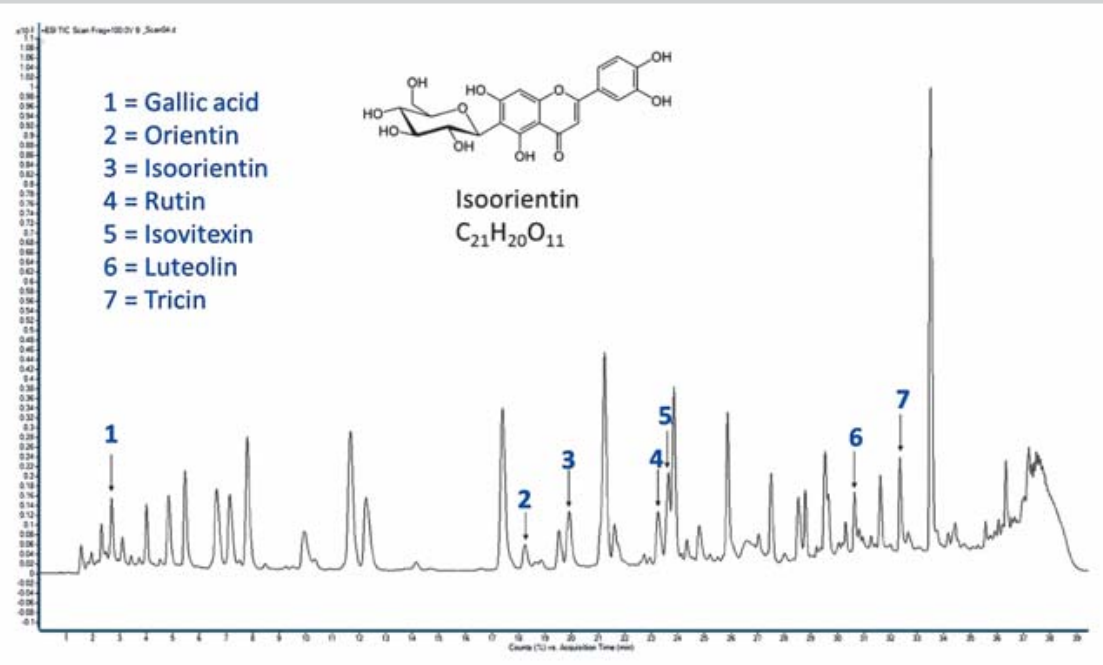

Fig. 1 LC-MS chromatogram of a P. edulis leaf extract representing the total ion chromatogram (TIC) with only flavonoids annotated. (Color figure available online only.)

Furthermore, it induces neutrophils to release lysosomal enzymes [5] and downregulates collagen expression by fibroblasts [6]. Just like IL-6, its production is stimulated by the presence of TNF- $\alpha$. VEGF is known to play a pivotal role in angiogenesis, but it is also involved in acute inflammatory processes. It can be considered a mitogen that regulates endothelial paracellular permeability and proliferation of mesenchymal cells. At the location of the wound and in the endothelial cells of the granulation tissue, VEGF and its receptors production are typically upregulated [7]. Cells in unhealed wounds constantly produce inflammatory mediators in an uncoordinated and self-sustaining phase of inflammation that impairs the restoration of anatomic and functional integrity in the normal period of time $[8,9]$. Thus, a prolonged inflammatory phase leads to delayed wound healing. Several wound-healing strategies are therefore under development which target the major phases of cutaneous wound healing: inflammation, proliferation, and tissue remodeling. In this regard, medicinal plants have always been the focus of several research programs to identify compounds with potential anti-inflammatory and wound-healing properties [10].

Phyllostachys edulis (Carrière) J. Houz. (Poaceae) is one of the most important Chinese bamboo species economically [11]. While bamboo stems are widely used in furniture production, the leaves are a by-product during harvesting. Thus, research projects focusing on the valorization of bamboo leaf products towards utilization in the nutrition or cosmetic industry have gained considerable attention. It was shown that bamboo leaf extract exerts potent antitumor, anti-inflammatory, antimicrobial, and anti-ulcerogenic activities [12-16]. Recently, a special bamboo gauze coated with polymer and drug was developed as a surgical bandage to facilitate faster wound healing [17]. It was the aim of the present study to investigate the anti-inflammatory and wound-healing potential of $P$. edulis leaf extract in in vitro models in comparison to the flavonoid isoorientin, which was identified as one of the major compounds.

\section{Results}

$\nabla$

In order to determine potential cytotoxic effects of bamboo leaf extract (BLE; $10-250 \mu \mathrm{g} / \mathrm{mL}$ ), isoorientin (5-100 $\mu \mathrm{M}$ ), and hydrocortisone $(5-100 \mu \mathrm{M})$ in HaCaT cells, the MTT assay was used.
Treatment with the different test compounds for $24 \mathrm{~h}$ at indicated concentrations had no significant cytotoxic effects on HaCaT cells. The cell viability for hydrocortisone ranged between $100-113 \%$, for BLE between $100-103 \%$, and for isoorientin between $93-100 \%$ (Fig. 1S, Supporting Information). Thus, the extract concentration ranged from $25-250 \mu \mathrm{g} / \mathrm{mL}$ for subsequent experiments. Isoorientin ( Fig. 1) was used in further experiments in concentrations ranging from $10-100 \mu \mathrm{M}$. Interestingly, hydrocortisone slightly increased cell viability in the used concentrations. However, no dose-dependent effect was observed. For subsequent experiments, hydrocortisone was used in a concentration of $10 \mu \mathrm{M}$ (or $3.6 \mu \mathrm{g} / \mathrm{mL}$, correspondingly).

To investigate whether BLE or isoorientin inhibit TNF- $\alpha$-induced IL-6, IL-8, and VEGF expression, HaCaT cells were treated with TNF- $\alpha(20 \mathrm{ng} / \mathrm{mL})$ after the preincubation of cells for $6 \mathrm{~h}$ with the various treatments. The results were compared to those of hydrocortisone $(10 \mu \mathrm{M}$ or $3.6 \mu \mathrm{g} / \mathrm{mL}$, correspondingly). BLE had no effect on the TNF- $\alpha$-induced production of IL-6 ( Fig. 2A). In contrast, isoorientin dose-dependently decreased IL-6 production in concentrations of $50 \mu \mathrm{M}$ and $100 \mu \mathrm{M}$ ( $\odot$ Fig. 2B). As presented in 0 Fig. $2 C$, the upregulation of IL- 8 by TNF- $\alpha$ treatment was dose-dependently reduced by BLE and isoorientin treatment ( Fig. 2D). The effects on the TNF- $\alpha$-induced production of VEGF are shown in $\odot$ Fig. $2 \mathrm{E}$ and F. BLE significantly decreased TNF- $\alpha$ stimulated VEGF production in HaCaT cells; isoorientin dose-dependently decreased TNF- $\alpha$-induced VEGF levels ( $\bullet$ Fig. 2 F).

The effects of BLE and isoorientin on the migration of 3T3 mouse fibroblasts were tested in an in vitro wound-healing model, in which wounds were generated using silicon culture inserts. Cells were allowed to migrate across the rectangular region of interest (ROI) into the center of the wound gap (width $450 \mu \mathrm{m}$ ) for $24 \mathrm{~h}$ at $37^{\circ} \mathrm{C}$. A clear difference was observed between cells treated with DMEM (0\% FCS) or with DMEM + $2 \%$ FCS (positive control) ( Fig. 3A-D). The addition of $2 \%$ FCS to the medium significantly increased cell migration over a period of $24 \mathrm{~h}$ resulting in a $65 \%$ closed wound gap. In contrast, in cells treated with DMEM without any FCS supplementation, the wound closure was approximately $20 \%$ after an observation period of $24 \mathrm{~h}$.

BLE in a concentration of $10 \mu \mathrm{g} / \mathrm{mL}$ significantly increased the cell migration rate when compared to the $0 \%$ FCS group ( $\bullet$ Fig. $3 \mathrm{~A}$ and C). A wound gap closure of approximately $55 \%$ was observed after $24 \mathrm{~h}$. In concentrations of $50 \mu \mathrm{g} / \mathrm{mL}$ and $100 \mu \mathrm{g} / \mathrm{mL}$ of BLE, 

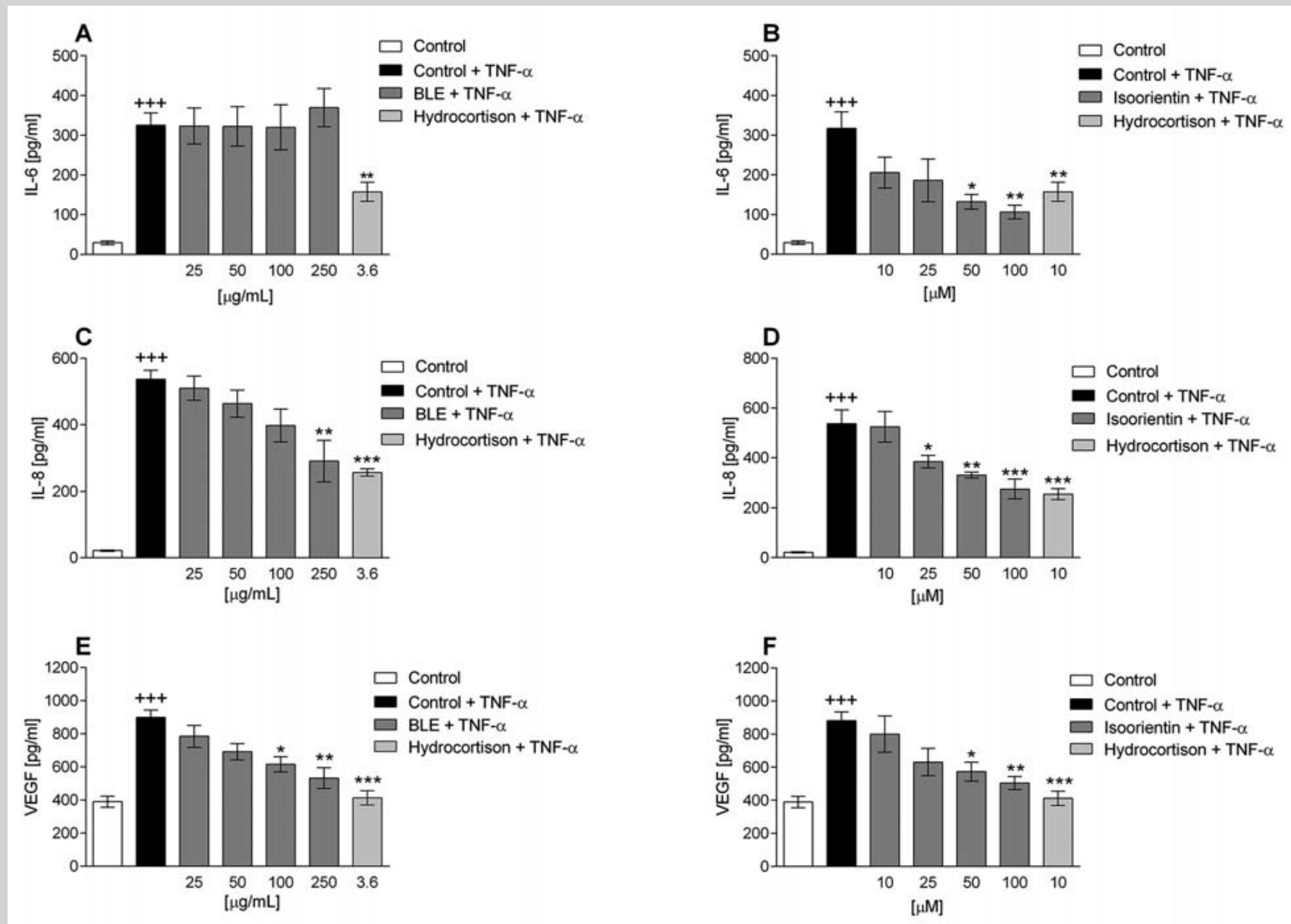

Fig. 2 Effects of bamboo leaf extract, isoorientin, and hydrocortisone on TNF- $\alpha$-induced $(20 \mathrm{ng} / \mathrm{mL}$ ) IL-6, IL-8, and VEGF secretion in HaCaT cells. IL-6, IL-8, and VEGF secretions were quantified by corresponding ELISA kits. Re-

sults are expressed as the mean \pm SD of four independent experiments. ${ }^{*} \mathrm{P}<0.05,{ }^{* *} \mathrm{p}<0.01$, and ${ }^{* * *} \mathrm{p}<0.001$ vs. TNF- $\alpha$-stimulated group; ${ }^{+++} p<0.001$ vs. untreated control group.
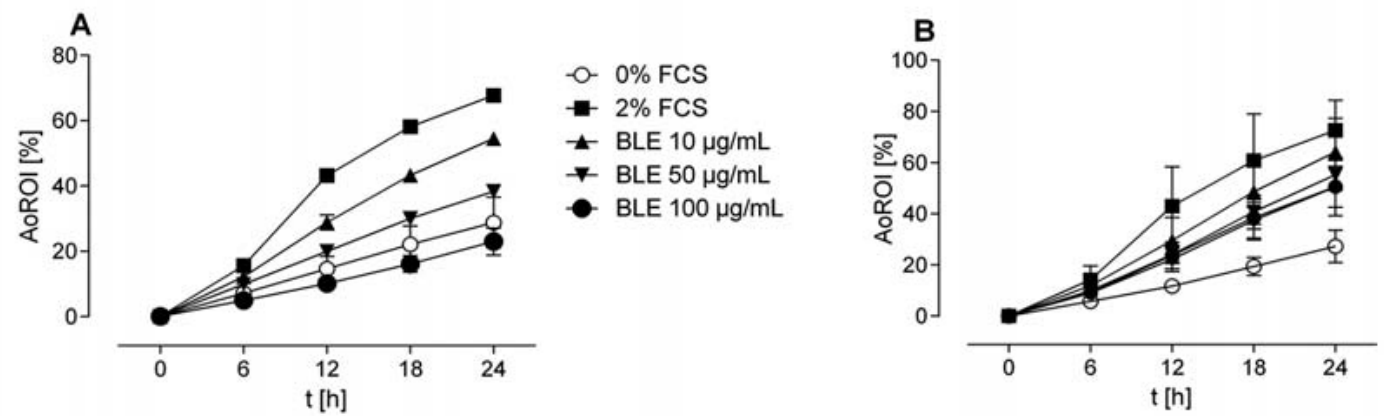

๑ $0 \%$ FCS

- $2 \% \mathrm{FCS}$

^ Isoorientin $10 \mu \mathrm{M}$

$\rightarrow$ Isoorientin $25 \mu \mathrm{M}$

- Isoorientin $50 \mu \mathrm{M}$

$\rightarrow$ Isoorientin $100 \mu \mathrm{M}$
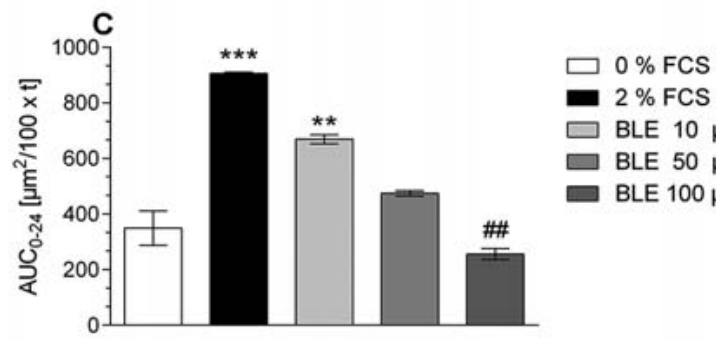

$2 \%$ FCS

$\square$ BLE $10 \mu \mathrm{g} / \mathrm{mL}$

$\square$ BLE $50 \mu \mathrm{g} / \mathrm{mL}$ $\square$ BLE $100 \mu \mathrm{g} / \mathrm{mL}$

Fig. 3 Effects of bamboo leaf extract and isoorientin on cell migration in 3T3 mouse fibroblasts. Graphs show the percentage of the predefined rectangle covered by cells over an observation period of $24 \mathrm{~h}(\mathbf{A}, \mathbf{B})$ and the corresponding area under the curve (AUC) in $\mu \mathrm{m}^{2} \times \mathrm{t}(\mathbf{C}, \mathbf{D})$. Data represent the mean \pm SD of two independent experiments. ${ }^{*} \mathrm{P}<0.05,{ }^{*} \mathrm{p}<0.01$, and ${ }^{* * *} \mathrm{p}<0.001$ vs. $0 \%$ FCS control group; ${ }^{\# \#} \mathrm{p}<0.01 \mathrm{vs.} 50 \mu \mathrm{g} / \mathrm{mL}$ BLE. 


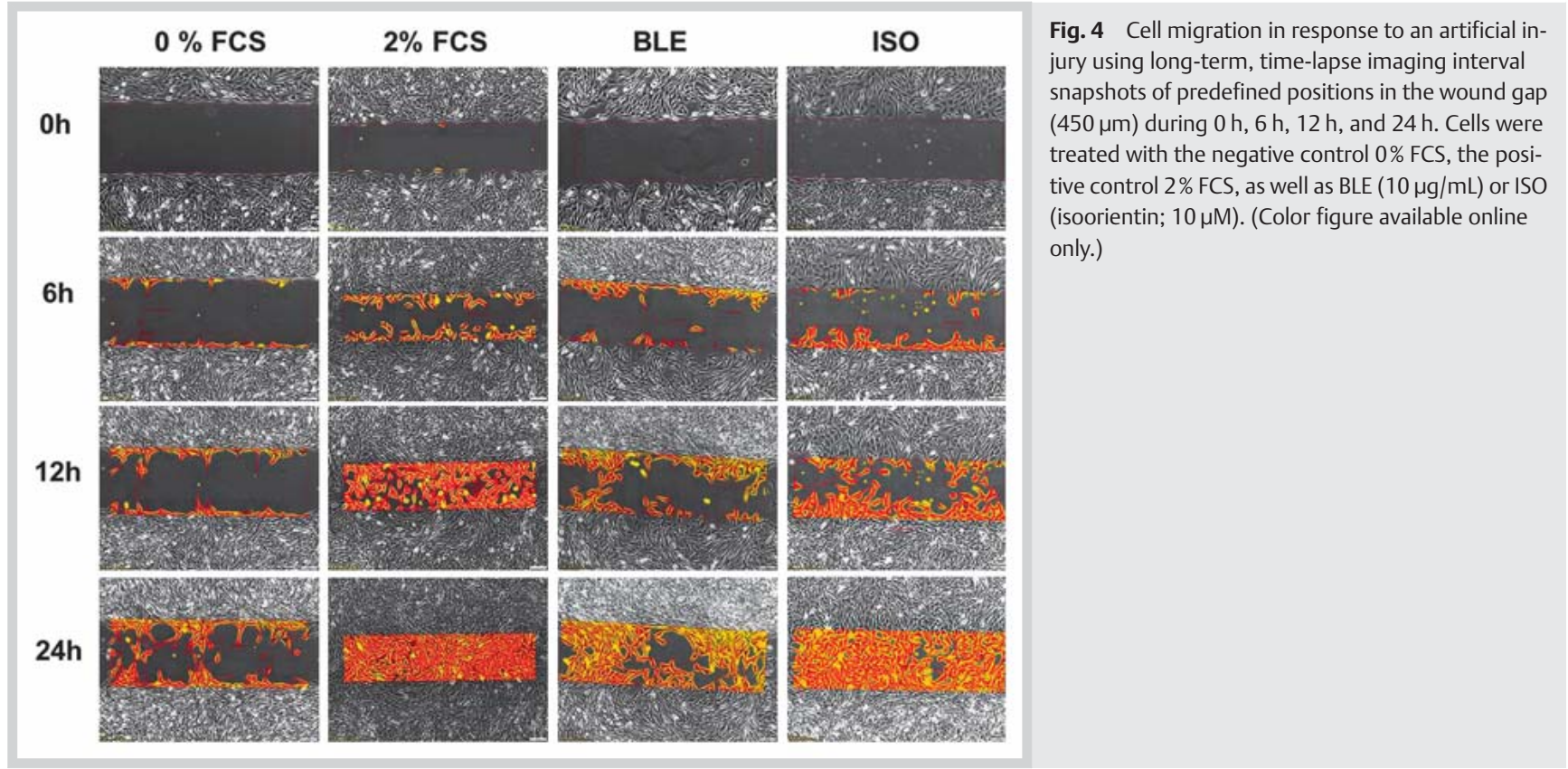

no statistically significant effects versus the $0 \%$ FCS control group were observed. However, multiple post hoc comparisons between groups revealed a significant difference between the $50 \mu \mathrm{g} / \mathrm{mL}$ and $100 \mu \mathrm{g} / \mathrm{mL}$ BLE groups $(\mathrm{p}<0.01$ ), indicating a stronger cell migration inhibitory effect in higher concentrations.

Isoorientin-treated cells started to migrate into the ROI at $6 \mathrm{~h}$ after removal of the silicon insert ( Fig. 3B). Interestingly, the 24-h migration rate was slightly higher in a concentration of $10 \mu \mathrm{M}$ than in higher concentrations, and after $24 \mathrm{~h}$, approximately $55 \%$ of the wound gaps were closed ( Fig. 3B). In addition, treatment with 25,50 , and $100 \mu \mathrm{M}$ of isoorientin could increase the overall migration rate within $24 \mathrm{~h}$, although no difference between the various concentrations could be observed (॰ Fig. 3D).

Since the area under the curve (AUC) and migration rate measurements showed only small statistical differences between the treatment groups, further image analyses were performed. It was of special interest to compare the effects of BLE and isoorientin in lower concentrations ( $\bullet$ Fig. 4). Using long-term, time-lapse imaging, interval snapshots of predefined positions in the gap during $0 \mathrm{~h}, 6 \mathrm{~h}, 12 \mathrm{~h}$, and $24 \mathrm{~h}$ were taken ( Fig. 4). Detailed image analysis showed that after $24 \mathrm{~h}$, BLE $(10 \mu \mathrm{g} / \mathrm{mL})$ and isoorientin $(10 \mu \mathrm{M})$ significantly increased cell migration into the ROI when compared to the $0 \%$ FCS negative control group. When compared to the $2 \%$ FCS positive control group, BLE and isoorientin achieved a wound gap closure of $55 \%$ after $24 \mathrm{~h}$.

\section{Discussion}

\section{$\nabla$}

Proinflammatory cytokines such as TNF- $\alpha$ and IL- 6 are increased in the inflammatory phase of wound healing [2]. While TNF- $\alpha$ at low concentrations promotes wound healing by stimulation of inflammation, it has a destructive effect on wound repair in higher concentrations [2]. IL-6 is produced in epidermal cells, fibroblasts, and dermal endothelial cells under normal conditions, but it is also synthesized by inflammatory cells infiltrating the skin in different pathological conditions [18]. Therefore, the inhi- bition of proinflammatory mediators secreted from activated keratinocytes may be an effective therapeutic approach to regulate the progression of the wound-healing process.

In the present study, the spontaneously immortalized human keratinocyte cell line HaCaT was used for the evaluation of antiinflammatory activities. HaCaT cells maintain normal keratinocyte morphology and full epidermal differentiation capacity and remain non-tumorigenic [19]. Like human primary keratinocytes, they produce cytokines and chemokines [20], which are involved in the development of inflammatory skin diseases.

Several plant extracts and natural compounds have been previously reported to have anti-inflammatory effects in activated keratinocytes [21-24]. In the present study, we found that BLE could not prevent the TNF- $\alpha$-mediated inflammatory response to IL-6 in HaCaT cells. It was demonstrated in a previous study that a hydroalcoholic extract prepared from the fresh leaves and branches of $P$. edulis significantly reduced IL-6 overproduction under lipotoxic conditions in murine C2C12, 3T3-L1, and Hepa6 cells [13], most likely through the activation of NF- $k$ B and AP-1 pathways. The different results of the two studies could be explained by either a different extract (fresh versus dry leaves) and/or different cell models.

When cells were pretreated with isoorientin $(50 \mu \mathrm{M}$ and $100 \mu \mathrm{M})$, the secretion of IL-6 was significantly reduced, comparable to that of the positive control hydrocortisone. IL- 6 inhibition by isoorientin was not due to a general cytotoxic effect, since cell viability in all cultures remained constant throughout the incubation period in the presence of all compounds tested. Anti-inflammatory activities of isoorientin have been reported in previous studies. For example, Conforti et al. [25] reported that isoorientin exerts significant anti-inflammatory activity through the inhibition of NO production in LPS-stimulated mouse macrophage RAW 264.7 cells, and Kupeli et al. [26] demonstrated a model of the inhibition of carrageenan-induced hind paw edema in mice. Further, our data on isoorientin are in good correlation with the data of Yuan et al. [27] who demonstrated that isoorientin significantly increased cell viability in mouse microglial (BV2) cells, blocked the protein expression of inducible nitric oxide 
synthase and cyclooxygenase-2, and decreased the production of nitric oxide and proinflammatory cytokines, including TNF- $\alpha$ and IL-1 $\beta$.

VEGF and the chemokine IL-8 play an important role in skin inflammation and are produced by activated keratinocytes [28, 29]. It has been demonstrated that TNF- $\alpha$ activates epidermal cells and induces the production of VEGF and IL-8 [30,31]. Both mediators are overexpressed in skin diseases that are associated with aberrant angiogenesis [32-34]. In the present study, BLE could reduce VEGF and IL- 8 levels induced by TNF- $\alpha$ in HaCaT cells. Isoorientin, which was identified as the main flavonoid in BLE, significantly reduced the TNF- $\alpha$-induced increase in VEGF and IL-8 production. To our knowledge, no data have been previously published on the effects of $P$. edulis extracts and isoorientin on the secretion of VEGF and IL-8. Isoorientin is one of the major active compounds in $P$. edulis that contributes to the moderate anti-inflammatory effects of the leaf extract by suppressing TNF$\alpha$-induced production of proinflammatory cytokines (IL-6), chemokines (IL-8), and VEGF in HaCaT keratinocytes. Thus, isoorientin might have potential as a therapeutic agent for inflammatory skin diseases. However, how much other polyphenols contribute to the overall activity of this plant and to what extent interactions among fractions and compounds are important for the activity needs to be investigated in further studies. Interestingly, extracts derived from either $P$. edulis or other bamboo species have shown potential anti-inflammatory activities $[12,15,35]$.

As mentioned previously, cutaneous tissue repair involves a complex reaction [36]. Fibroblasts play a critical role in normal wound healing. They are involved in key processes such as forming granulation tissue by proliferating and migrating, and creating new collagen structures to support the other cells associated with effective wound healing, as well as contracting the wound $[37,38]$. Thus, it was of interest to investigate the effects of BLE as well as of isoorientin on this cell type to reveal if these compounds can contribute to the wound-healing process. We performed a modification of the classical scratch assay by using cell seeding stoppers, which were applied to the plate bottom. After the cells reached confluence, the inserts were removed causing a gap of $450 \mu \mathrm{m}$. The cells then migrated across the created gap. Long-term, time-lapse imaging was performed by taking interval snapshots of predefined positions in the gap during a 24-h period, thus minimizing errors compared to other methods that measure wound closure. This is an accurate and reproducible model to study wound healing by monitoring cell migration over an extended period.

Wound closure was improved by 28\% (12 h) and 54\% (24 h), respectively, in the presence of $10 \mu \mathrm{g} / \mathrm{mL}$ BLE. Interestingly, a higher concentration of BLE inhibited cell migration without affecting cell viability. Isoorientin at a concentration of $10 \mu \mathrm{M}$ improved wound closure by 29\% (12 h) and 56\% (24 h), respectively. Similar to BLE, higher concentrations of isoorientin prevented cell migration into the area of interest without considerable toxic effects. Based on these findings, we hypothesize that the inhibition of cell migration of fibroblasts in a collagen matrix could be a result, in part, of the reduction of VEGF secretion. Our data show that TNF$\alpha$-induced VEGF secretion was decreased at higher doses of BLE and isoorientin. We therefore suggest that BLE as well as isoorientin might have a dual activity - in higher doses $(>100 \mu \mathrm{g} / \mathrm{mL}$ extract or $>25 \mu \mathrm{M}$ isoorientin) the compounds show an anti-inflammatory effect, while in lower concentrations $(\leq 10 \mu \mathrm{g} / \mathrm{mL}$ extract or $\leq 10 \mu \mathrm{M}$ isoorientin), both compounds exert anti-angio- genic activities by inhibiting migration, possibly by prevention of VEGF secretion.

In conclusion, natural accelerators of cutaneous tissue repair with simultaneous anti-inflammatory activities are of great interest for a variety of dermatological disorders. Thus, treatment with $P$. edulis leaf extract or isoorientin may be a potential therapeutic strategy to promote wound healing and to prevent inflammation in a persistent inflammatory condition. Further investigations of the precise mechanism by which $P$. edulis and isoorientin reveal anti-inflammatory as well as wound-healing properties are currently underway.

\section{Materials and Methods \\ $\nabla$}

\section{Materials}

4',6-Diamidino-2-phenylindole dihydrochloride, DMSO, acetic acid $99,7 \%$, sodium dodecyl sulfate (SDS), isoorientin (purity $>98 \%$ ), hydrocortisone (purity >98\%), and MTT (purity 98\%) were purchased from Sigma-Aldrich. IL-6, IL-8, and VEGF human ELISA kits were purchased from LuBioScience. Ibidi culture inserts for live cell analysis were obtained from Vitaris AG. Dulbecco's PBS [-] $\mathrm{CaCl}_{2}$ [-] $\mathrm{MgCl}_{2}$ was purchased from LuBio Science Invitrogen. Recombinant human TNF- $\alpha$ (purity $>97 \%$ ) was purchased from R\&D Systems. Collagen type I rat tail solution (purity $>90 \%$ ) was purchased from BD Biosciences.

\section{Cell culture}

Human HaCaT cells from histologically normal skin and Swiss 3T3 albino mouse fibroblasts (both from Cell Line Services) were maintained in Dulbecco's modified Eagle's medium supplemented with $1 \%$ penicillin $10000 \mathrm{U} / \mathrm{mL} /$ streptomycin $10000 \mu \mathrm{g} /$ $\mathrm{mL}$, and $10 \%$ fetal calf serum (FCS) (all from LuBio Science) at $37^{\circ} \mathrm{C}$ in a humidified atmosphere containing $5 \% \mathrm{CO}_{2}$ [19].

\section{Plant material and extract preparation}

The plant material of $P$. edulis was provided by Organic Bamboo Industries. It was identified by Mr. Liao Rong Qi, Forest Chief of Yangzhuang Town Station, WuYiShan, Fujian, China. Dried bamboo leaves $(0.5 \mathrm{~g}$ ) were ground and extracted by Soxhlet extraction with water $(30 \mathrm{~mL})$ and finally lyophilized (final yield $100 \mathrm{mg}$ ). Voucher specimens of the corresponding extract (ICB_BLE2013_10) are deposited at the Institute for Chemistry and Bioanalytics, School of Life Sciences, University of Applied Sciences Northwestern Switzerland. The purified extract was separated on a Zorbax SB phenyl column $(3.0 \times 150 \mathrm{~mm}, 1.8 \mu \mathrm{m})$ in gradient mode (25-95 B \%, A water, B methanol plus 0.1 formic acid) with a flow rate of $0.4 \mathrm{~mL} / \mathrm{min}$ at $35^{\circ} \mathrm{C}$. The injection volume was set to $1 \mu \mathrm{L}$. Analysis was performed on an Agilent 6410 triple quadrupol mass spectrometer with an electrospray ionization source operated in the positive mode with an Agilent 1200SL HPLC system running under MassHunter B05.02. The amounts of the major flavonoids were quantified using an LC-MS/MS method. The quantification of individual flavonoids was performed by separate LC-MS/MS (SRM) experiments (data not shown). Isoorientin ( Fig. 1) was detected as one of the main flavonoids with an amount of $5.32 \mathrm{~g} / \mathrm{kg}$. A flavonoid profile of a bamboo leaf aqueous extract is shown in $\bullet$ Fig. 1. 


\section{Cell viability assay}

To assess cell viability, the MTT test was conducted. Therefore, $200 \mu \mathrm{L}$ of the HaCaT cell suspension was seeded into 96-well plates at a concentration of $6 \times 10^{4}$ cells/well followed by an incubation period of $24 \mathrm{~h}\left(37^{\circ} \mathrm{C}, 5 \% \mathrm{CO}_{2}\right)$. After the incubation time, the medium was discarded and the cells were washed with $150 \mu \mathrm{L}$ PBS. The samples solved in DMEM were added in a dilution series. All sample solutions were dissolved in serum-free medium. The extract was tested in concentrations of $10,25,50$, 100 , and $250 \mu \mathrm{g} / \mathrm{mL}$ hydrocortisone (positive control), and isoorientin was tested in concentrations of $5,10,25,50$, and $100 \mu \mathrm{M}$. Four independent experiments were conducted in triplicate. The controls consisted of wells with or without cells with pure DMEM or the solvent standard DMSO. After an incubation period of $24 \mathrm{~h}$, $10 \mu \mathrm{L}$ of MTT solution ( $5 \mathrm{mg} / \mathrm{mL}$ PBS) was added and again incubated for $2 \mathrm{~h}$. The liquid was discarded before adding $100 \mu \mathrm{L}$ of the cell lysis buffer consisting of 99.4\% DMSO, 0.6\% acetic acid, and SDS $0.1 \mathrm{~g} / \mathrm{mL}$. The optical density was read at 570 and $630 \mathrm{~nm}$ as a reference on a microplate reader (SpectraMax M2e). The viability was calculated according to the formula:

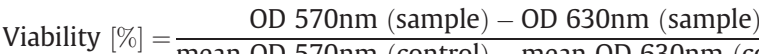
mean OD 570nm (control) - mean OD 630nm (control)

The experiments were executed utilizing cell culture passage numbers from 35 to 70

\section{Anti-inflammatory activity}

The experimental setup as well as the concentration of TNF- $\alpha$ for these experiments was chosen according to Park et al. [23], with some modifications. Briefly, HaCaT cells $\left(7 \times 10^{5}\right.$ cells per well, 12 -well plates) were preincubated in a culture incubator for $6 \mathrm{~h}$ with or without the addition of different concentrations of BLE $(25-250 \mu \mathrm{g} / \mathrm{mL})$ or isoorientin $(10-100 \mu \mathrm{M})$, or with the positive control hydrocortisone $(10 \mu \mathrm{M})$ before adding the proinflammatory cytokine TNF- $\alpha$. After a preincubation time of $6 \mathrm{~h}$, TNF- $\alpha$ $(20 \mathrm{ng} / \mathrm{mL}$ ) was added, and the cells were incubated for a further $24 \mathrm{~h}$. After a total incubation time of $30 \mathrm{~h}$, VEGF, IL-8, and IL-6 were measured in cell supernatants using enzyme-linked immunosorbent assay kits as biomarkers of the anti-inflammatory response according to manufacturer's instructions. The absorbance was measured at $450 \mathrm{~nm}$ using a microplate reader (SpectraMax M2e).

\section{Cell migration assay (wound-healing scratch assay)}

After positioning the cell culture inserts in the 12-well dishes, the 3T3 mouse fibroblasts were inoculated in a concentration of $4 \times 10^{5}$ cells $/ \mathrm{mL}$ into the collagen-coated wells. After an incubation time of $24 \mathrm{~h}$, the cells reached confluence, and the inserts were removed causing a gap of $450 \mu \mathrm{m}$. The subsequent washing with $1 \mathrm{~mL}$ PBS was followed by the manual addition of a scratch on the side of the well by a $100-\mu \mathrm{L}$ pipette tip. In different concentrations accordingly, the wells were charged with the test compounds. BLE and isoorientin were dissolved in DMEM containing $0.2 \%$ FCS. DMEM supplemented with $2 \%$ FCS was used as a positive control and 0\% FCS (DMEM without supplements) was used as a negative control. Long-term, time-lapse imaging was performed using the Olympus IX83 automated inverted microscope platform for live cell imaging. Interval snapshots of predefined positions in the gap during $24 \mathrm{~h}$ were taken. Exact positions were defined in each gap of every well by using the Olympus software package cellSens Dimension 1.81 and the cells were observed for $24 \mathrm{~h}$. BLE was in concentrations of 10,50 , and $100 \mu \mathrm{g} /$
$\mathrm{mL}$, and isoorientin in concentrations of $10,25,50$, and $100 \mu \mathrm{M}$. All experiments were conducted using passage numbers from 43 to 50.

\section{Statistics}

Data are shown as mean \pm SD. All experiments were performed in triplicate, and each experiment was repeated four times. Statistical analysis of the data was carried out by one-way analysis of variance (ANOVA) followed by Dunnett's and Tukey's multiple comparison tests using the software package GraphPad Prism (version 5.01, GraphPad Software, Inc.). In all cases, differences were considered significant if $\mathrm{p}<0.05$.

The following computerized approach was used for evaluating cell migration: After selecting a rectangle (ROI) in the cell-free gap with appropriate software tools, the area was calculated in $\left[\mu \mathrm{m}^{2}\right]$ automatically and set as $0 \% \mu \mathrm{m}^{2}$ covered surface (defined as the area of region of interest, AoROI). Due to the migration of the cells into the ROI, the value for AoROI of the covered surface increased over time. The principle of measurement was based on a modified pixel counting by the software package. At $t=6,12$, 18 , and $24 \mathrm{~h}$, the AoROI was measured and its value was plotted in graphs. The $\mathrm{AUC}_{24 \mathrm{~h}}$ was computed by GraphPad Prism software and depicts the magnitude of wound closure in one value.

\section{Supporting Information}

Fig. 1S, showing the cell viability data, can be found as Supporting Information.

\section{Conflict of Interest}

$\nabla$

The authors declare no conflict of interest.

\section{References}

1 Strodtbeek F. Physiology of wound healing. Newborn Infant Nurs Rev 2001; 1 : 43-52

2 Singer AJ, Clark RAF. Mechanisms of disease: cutaneous wound healing. New Engl J Med 1999; 341: 738-746

3 Gurtner GC, Werner S, Barrandon Y, Langaker MT. Wound repair and regeneration. Nature 2008; 453: 314-321

4 Stenvinkel P, Ketteler M, Johnson RJ, Lindholm B, Pecoits-Filho R, Riella M, Heimburger O, Cederholm T, Girndt M. IL-10, IL-6, and TNF-alpha: central factors in the altered cytokine network of uremia-the good, the bad, and the ugly. Kidney Int 2005; 67: 1216-1233

5 Walz A, Peveri P, Aschauer H, Baggiolini M. Purification and amino-acid sequencing of NAF, a novel neutrophil-activating factor produced by monocytes. Biochem Bioph Res Co 1987; 149: 755-761

6 Unemori EN, Amento EP, Bauer EA, Horuk R. Melanoma growth-stimulatory activity/GRO decreases collagen expression by human fibroblasts. Regulation by C-X-C but not C-C cytokines. J Biol Chem 1993; 268: 1338-1342

7 de Vries C, Escobedo JA, Ueno H, Houck K, Ferrara N, Williams LT. The fms-like tyrosine kinase, a receptor for vascular endothelial growth factor. Science 1992; 255: 989-991

8 Heinlin J, Schreml S, Babilas P, Landthaler M, Karrer S. Cutaneous wound healing. Therapeutic interventions. Hautarzt 2010; 61: 611-626

9 Schreml S, Szeimies RM, Prantl L, Landthaler M, Babilas P. Wound healing in the 21st century. J Am Acad Dermatol 2010; 63: 866-881

10 Reuter J, Merfort I, Schempp CM. Botanicals in dermatology: an evidence-based review. Am J Clin Dermatol 2010; 11: 247-267

11 Oprins J, Van Trier H. Bamboo, a material for landscape and garden design. Basel: Birkhäuser Publishers; 2006

12 Higa JK, Liang Z, Williams PG, Panee J. Phyllostachys edulis compounds inhibit palmitic acid-induced monocyte chemoattractant protein 1 (MCP-1) production. PLoS One 2012; 7: e45082

13 Higa JK, Panee J. Bamboo extract reduces interleukin 6 (IL-6) overproduction under lipotoxic conditions through inhibiting the activation of NF-kappa B and AP-1 pathways. Cytokine 2011; 55: 18-23 
14 Jung SH, Lee JM, Lee HJ, Kim CY, Lee EH, Um LH. Aldose reductase and advanced glycation endproducts inhibitory effect of Phyllostachys nigra. Biol Pharm Bull 2007; 30: 1569-1572

15 Kim SH, Kim TS, Kim SJ, Seong CN, Lee OH, Lee HJ, Yoo JC. Inhibition of interleukin-12 production in mouse macrophages via suppression of nuclear factor-kappa B binding activity by Phyllostachys nigra var. henonis. Immunopharm Immunot 2007; 29: 131-139

16 Kim SH, Kim TS, Lee HJ, Yoo JC. Enhancement of 1, 25-dihydroxyvitamin D-3- and all-trans retinoic acid-induced differentiation of human leukemia HL-60 cells by Phyllostachys nigra var. henonis. Immunopharm Immunot 2007; 29: 119-129

17 Shanmugasundaram OL, Gowda RVM. Development and characterization of bamboo gauze fabric coated with polymer and drug for wound healing. Fiber Polym 2011; 12: 15-20

18 Paquet P, Pierard GE. Interleukin-6 and the skin. Int Arch Allergy Immunol 1996; 109: 308-317

19 Boukamp P, Petrussevska RT, Breitkreutz D, Hornung J, Markham A, Fusenig NE. Normal keratinization in a spontaneously immortalized aneuploid human keratinocyte cell line. J Cell Biol 1988; 106: 761-771

20 Pastore S, Lulli D, Potapovich AI, Fidanza P, Kostyuk VA, Dellambra E, De Luca C, Maurelli R, Korkina LG. Differential modulation of stress-inflammation responses by plant polyphenols in cultured normal human keratinocytes and immortalized HaCaT cells. J Dermatol Sci 2011; 63: 104-114

21 Kao ES, Hsu JD, Wang CJ, Yang SH, Cheng SY, Lee HJ. Polyphenols extracted from Hibiscus sabdariffa L. inhibited lipopolysaccharide-induced inflammation by improving antioxidative conditions and regulating cyclooxygenase-2 expression. Biosci Biotechnol Biochem 2009; 73: 385-390

22 Kim HJ, Xu L, Chang KC, Shin SC, Chung JI, Kang D, Kim SH, Hur JA, Choi TH, Kim S, Choi J. Anti-inflammatory effects of anthocyanins from black soybean seed coat on the keratinocytes and ischemia-reperfusion injury in rat skin flaps. Microsurgery 2012; 32: 563-570

23 Park K, Lee JH, Cho HC, Cho SY, Cho JW. Down-regulation of IL-6, IL-8, TNF-alpha and IL- 1 beta by glucosamine in HaCaT cells, but not in the presence of TNF-alpha. Oncol Lett 2010; 1: 289-292

24 Park YM, Noh SU, Kim HS, Kang H, Lee JY, Kim HO. Epigallocatechin-3gallate has an anti-inflammatory effect by regulating macrophage migration inhibitory factor-induced thelper related chemokines and cytokines in human HaCaT cells. Clin Immunol 2010; 135 (Suppl.): S124S125
25 Conforti F, Rigano D, Menichini F, Loizzo MR, Senatore F. Protection against neurodegenerative diseases of Iris pseudopumila extracts and their constituents. Fitoterapia 2009; 80: 62-67

26 Kupeli E, Aslan M, Gurbuz I, Yesilada E. Evaluation of in vivo biological activity profile of isoorientin. Z Naturforsch C 2004; 59: 787-790

27 Yuan L, Wang J, Xiao HF, Wu WQ Wang YT, Liu XB. MAPK signaling pathways regulate mitochondrial-mediated apoptosis induced by isoorientin in human hepatoblastoma cancer cells. Food Chem Toxicol 2013; 53: $62-68$

28 Takematsu H, Tagami $H$. Mode of release of interleukin-8 from proliferating human epidermal keratinocytes in vitro. Exp Dermatol 1993; 2: 121-124

29 Viac J, Palacio S, Schmitt D, Claudy A. Expression of vascular endothelial growth factor in normal epidermis, epithelial tumors and cultured keratinocytes. Arch Dermatol Res 1997; 289: 158-163

30 Frank S, Hubner G, Breier G, Longaker MT, Greenhalgh DG, Werner S. Regulation of vascular endothelial growth factor expression in cultured keratinocytes. Implications for normal and impaired wound healing. J Biol Chem 1995; 270: 12607-12613

31 Larsen CG, Anderson AO, Oppenheim JJ, Matsushima K. Production of interleukin- 8 by human dermal fibroblasts and keratinocytes in response to interleukin-1 or tumour necrosis factor. Immunology 1989; 68: 31-36

32 Pietrzak AT, Zalewska A, Chodorowska G, Krasowska D, Michalak-Stoma A, Nockowski P, Osemlak P, Paszkowski T, Rolinski JM. Cytokines and anticytokines in psoriasis. Clin Chim Acta 2008; 394: 7-21

33 Smith JR, Lanier VB, Braziel RM, Falkenhagen KM, White C, Rosenbaum $J T$. Expression of vascular endothelial growth factor and its receptors in rosacea. Br J Ophthalmol 2007; 91: 226-229

34 Xia YP, Li B, Hylton D, Detmar M, Yancopoulos GD, Rudge JS. Transgenic delivery of VEGF to mouse skin leads to an inflammatory condition resembling human psoriasis. Blood 2003; 102: 161-168

35 Choi YJ, Lim HS, Choi JS, Shin SY, Bae JY, Kang SW, Kang IJ, Kang YH. Blockade of chronic high glucose-induced endothelial apoptosis by $\mathrm{Sa}$ sa borealis bamboo extract. Exp Biol Med 2008; 233: 580-591

36 Werner S, Krieg T, Smola $H$. Keratinocyte-fibroblast interactions in wound healing. J Invest Dermatol 2007; 127: 998-1008

37 Bainbridge $P$. Wound healing and the role of fibroblasts. J Wound Care 2013; 22: 407-408, 410-412

38 Baum CL, Arpey CJ. Normal cutaneous wound healing: clinical correlation with cellular and molecular events. Dermatol Surg 2005; 31: 674686 